\title{
Special Issue on Animals and Philosophy
}

\author{
Gonzalo Villanueva ${ }^{1}$
}

Published online: 25 April 2018

(C) Springer Science+Business Media B.V., part of Springer Nature 2018

We are currently living in an era that is increasingly referred to as the Anthropocene, a human-dominated, geological epoch. Although human's world-altering abilities date back to the Agricultural Revolution, in the last few centuries, our collective activity has resulted in increasing greenhouses gases, rising global temperatures, an accumulation of nitrogen on land and water, the acidification of the oceans, large-scale deforestation and habitat loss, pollution (including from disposable plastics), and decreasing biodiversity. We have the dishonourable distinction of ushering in the sixth mass extinction: an estimated one-third of reef-building corals, a quarter of all mammals, a fifth of all reptiles, and a sixth of all birds face annihilation. This is an extinction event unseen since the dinosaurs disappeared 65 million years ago. Human population has contributed to the emergence of the Anthropocene and to many of the problems we face. Today, there are 7.3 billion people on the planet and that number is due to climb to 9.7 billion by 2050. Affluent lifestyles in the world's richest countries, which have comparatively smaller populations, have caused a higher percentage of environmental harm than non-developed countries. Furthermore, as newly industrialised nations, China and India account for approximately $36 \%$ of global carbon emissions. The current ecological crisis is indeed a global crisis.

The fate of the world's farmed animals, particularly those reared in industrial settings, is one of the most significant ethical issues in the era of the Anthropocene. According to historian Yuval Noah Harai, nonhuman animals 'are the main victims of history, and the treatment of domesticated animals in industrial farms is perhaps the worst crime in history'. There are more domesticated animals than humans living today. Therefore, their lives and their treatment concern the majority of the world's sentient creatures. Animal agriculture, argues Harari, is responsible for more pain and suffering than all the wars throughout human history put together. Affluent societies rear and slaughter billions of animals each year for their flesh and products, and they consume it in abundant, unsustainable levels: in Australia alone, the average person eats about

Gonzalo Villanueva

villanueva.g@unimelb.edu.au

1 School of Historical and Philosophical Studies, The University of Melbourne, Parkville,

VIC, Australia 
$111 \mathrm{~kg}$ of meat each year. Meanwhile, nations like India and China, with their large and growing populations, look to adopt western, meat-centric lifestyles. The number of animals suffering in farms across the world is growing, not declining.

Seeking to contest the politics and culture of animal exploitation, today there are small and large animal protection organisations, as well as grassroots groups and countless individuals, who campaign on important issues: farmed animals, animals in research, animals used in sports and entertainment, and wild animals. Importantly, concern for the wellbeing and rights of animals is an issue that people across nations, cultures, and beliefs care deeply about. Empathy for animals transcends class, gender, sex, race, and age. Increasingly, those who reject and oppose the exploitation of animals are choosing one of the most effective approaches to resisting the multibillion dollar animal industrial complex: veganism. Animal rights and veganism have become practically synonymous.

Consideration for the moral status of animals can be traced throughout Eastern and Western thought. In more recent times, the humanities have undergone an 'animal turn', and scholarship on animals across all disciplines has grown significantly. This special edition of Sophia seeks to contribute to this rich conversation. Since its creation in 1962, Sophia has sought to provide a forum for discussing questions of philosophy and traditions. Unfortunately, concerns for animals have rarely entered this forum. With this special edition of Sophia, this gap is starting to be rectified. This edition has provided a valuable space for the contemplation of animal ethics from various perspectives, from Hinduism, Buddhism, Jainism, and Christianity to secular thinking. Hopefully, this edition serves as inspiration for others to continue this important conversation about animals.

This edition starts in the recent past. Over forty years ago, Peter Singer's 1975 book Animal Liberation inspired, rejuvenated, and reignited the animal movement across the world. In the early 1970s, Singer was an unknown, young philosopher from Melbourne, Australia. Today, he is one of the most influential living philosophers. Gonzalo Villanueva's article 'Against Animal Liberation? Peter Singer and His Critics' explores Singer's animal ethics and his principle of 'equal consideration of interests' that politicised and persuaded so many people to take up the animal cause. In particular, Villanueva's article examines the philosophical debate that unfolded in the years following the publication of Singer's thesis. It explores the responses from his ardent critics and why some of them changed their minds.

Zeynep Direk's contribution 'Animality in Lacan and Derrida: The Deconstruction of the Other' explores issue of animality in the works of Derrida and Lacan. In his paper, Direk examines Derrida's intellectual engagement with Lacan's notion of subjectivity and his rejection of animals of subjects. On the other hand, Derrida argues that animality cannot be excluded from subjectivity. Direk suggests that 'Derrida's resistance to exclude animality from ethical agency does not make animals ethical actors; however, it paves the way for considering animals as partners in ethical relations'.

Chad Engelland's article 'Heidegger and the Question of Human Animality' contends that human difference and human animality are not mutually exclusive. Engelland argues that Heidegger has the necessary conceptual resources 'to affirm human animality while safeguarding the human difference'. Engelland's main point is that although humans are indeed animals, it is the arguable human openness to being which 'takes up and transfigures the significance of our animal inheritance'. 
Mary A. Ashley's paper 'In Communion with God's Sparrow: Incorporating Animal Agency into the Environmental Vision of Laudato Si' explores recent Catholic teaching on animals and environmentalism. Ashley argues that Catholic teaching orientated toward a cross-species communion should go beyond the present form of humananimal relations and incorporate an alternative view of animal agency as advanced by Merleau-Pontyan phenomenology. Although 'one can meet a physical need in a mechanical way', suggests Ashley, 'one must incorporate animal agency to attain Laudato Si's vision of communion'.

Joshua C. Thurow's contribution 'Animals with Soul' argues that ensouled animalism, which is a variation of animalism, has advantages over other rival conceptions, namely materialistic animalism and pure dualism. Thurow is not arguing about the existence of souls or indeed animalism. Instead, Thurow's aim is to argue that ensouled animalism has attractive features that believers in souls have reason to accept: 'how physical predications can literally be true of us and it can straightforwardly explain how we can survive death'.

Christopher Chapple's contribution on 'Animal Ethics' explores the moral status of animals not by discussing the issue through 'normative, rational ethics', but with a focus on a 'narrative, emotive approach'. The article begins with Chapple's personal story of coming to terms with animals, ethics, and vegetarianism. Chapple then takes us through Hindu, Buddhist, and Jaina stories in which nonhuman animals signal a shift 'from rigidity toward a larger sense of what defines being'. Ultimately, Chapple suggests that 'the acknowledgement of the existence of animal consciousness need not necessarily rely upon its current scientistic justifications'.

Purushottama Bilimoria's article 'Animal Justice and Moral Mendacity' examines the sentiments we have toward animals in juxtaposition to the claims in Hindu/ Jaina and Judaic theologies. In relation to the animal question, Bilimoria asks how sophisticated and profound is the appreciation of the issues that are currently being debated in contemporary circles? What degree of awareness is evident in the traditions, in the actual explanatory and morally sensitised senses? Bilimoria states 'we should like to think that human beings are intelligent enough to be able to come to terms with the fact that they have certain basic duties to other species in the common eco-sphere'.

Veena Rani Howard's contribution 'Lessons from "The Hawk and Dove": Reflections on the Mahābhārata's Animal Parables and Ethical Predicaments' asks why do gods in these stories disguise themselves as animals in order to demonstrate a moral point? Howard suggests that 'animals appearing in the stories in the Mahābhārata must be taken seriously as sites where complex - and radical - ethical issues are expressed and, as such, cannot be read solely as means for ideological or pedagogical ends'. Through these Hindu parables, Howard demonstrates how animals disrupt anthropocentrism.

Finally, Yamini Narayanan's article 'Cow protection for the cows: critiquing Hinduism's milking, mothering legends' offers a much needed critical perspective on the myth of the holy Hindu cow. It is a timely contribution because India has the highest livestock population in the world and is one of the largest beef exporters. Yet, India has no formal cattle beef industry; rather, it is the so-called sacred dairy cows, along with bulls and male calves, that contribute to India's enormous beef economy. By applying a feminist vegan critique to Hindu theology, Narayanan argues that in order to interpret 
the Hindu ethic of cow protectionism in ways that genuinely protect cows from exploitation, then it is 'vital to problematise the significance and use of cow milk in Hindu beliefs, rituals and identity'. In her critique of two Hindu legends, Narayanan contends that the depiction of sacred cow's milk in these myths can be interpreted as actually being derived from plants and is vegan. 